
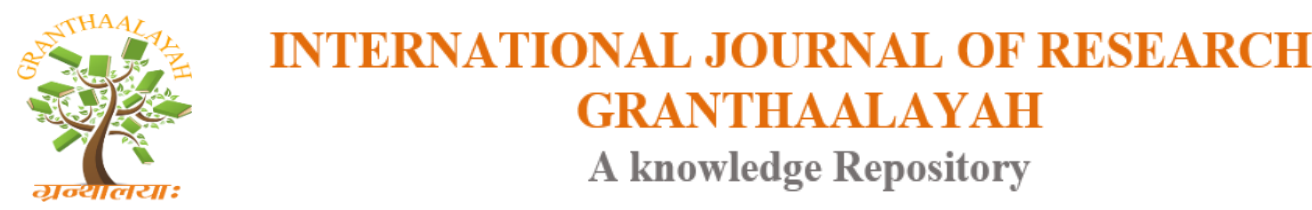

Science

\title{
LESSENING OF ACTUAL POWER LOSS BY MODIFIED ALGORITHM
}

\author{
Dr. K. Lenin *1 \\ ${ }^{* 1}$ Professor, Department of EEE Prasad V.Potluri Siddhartha Institute of Technology, Kanuru, \\ Vijayawada, Andhra Pradesh, India
}

\begin{abstract}
This paper presents a Modified Teaching-Learning-Based Optimization (MTLBO) algorithm for solving reactive power flow problem. Basic Teaching-Learning-Based Optimization (TLBO) is reliable, accurate and vigorous for solving the optimization problems. Also, it has been found that TLBO algorithm slow in convergence due to its high concentration in the accuracy. This paper presents an, Modified version of TLBO algorithm, called as Modified Teaching-Learning-Based Optimization (MTLBO). A parameter called as "weight" has been included in the fundamental TLBO equations \& subsequently it increases the rate of convergence. In order to evaluate the proposed algorithm, it has been tested in practical 191 test bus system. Simulation results reveal about the better performance of the proposed algorithm in reducing the real power loss \& voltage profiles are within the limits.
\end{abstract}

Keywords: Optimal Reactive Power; Transmission Loss; Modified Teaching Learning.

Cite This Article: Dr. K. Lenin (2018). "LESSENING OF ACTUAL POWER LOSS BY MODIFIED ALGORITHM” International Journal of Research - Granthaalayah, 6(8), 159-167. https://doi.org/10.29121/granthaalayah.v6.i8.2018.1418.

\section{Introduction}

Optimal reactive power dispatch problem is one of the difficult optimization problems in power systems \& various mathematical techniques [1-7] have been utilized to solve the problem. Recently many types of Evolutionary algorithms [8-9] have been used to solve the reactive power problem. This paper presents a Modified Teaching-Learning-Based Optimization (MTLBO) algorithm for solving reactive power flow problem. Basic Teaching-Learning-Based Optimization (TLBO) [10-16] is reliable, accurate and vigorous for solving the optimization problems. Also it has been found that TLBO algorithm slow in convergence due to its high concentration in the accuracy. This paper presents an, Modified version of TLBO algorithm, called as Modified Teaching-Learning-Based Optimization (MTLBO). A parameter called as "weight" has been included in the fundamental TLBO equations \& subsequently it increases the rate of convergence. In order to evaluate the proposed algorithm, it has been tested in practical 191 test bus system. Simulation results reveal about the better performance of the proposed algorithm in reducing the real power loss \& voltage profiles are within the limits. 


\section{Objective Function}

\section{Active Power Loss}

The objective of the reactive power dispatch is to minimize the active power loss in the transmission network, which can be described as follows:

$F=P L=\sum_{k \in N b r} g_{k}\left(V_{i}^{2}+V_{j}^{2}-2 V_{i} V_{j} \cos \theta_{i j}\right)$

Where $\mathrm{F}$ - objective function, $\mathrm{P}_{\mathrm{L}}$ - power loss, $\mathrm{g}_{\mathrm{k}}$-conductance of branch, $\mathrm{V}_{\mathrm{i}}$ and $\mathrm{V}_{\mathrm{j}}$ are voltages at buses $\mathrm{i}, \mathrm{j}, \mathrm{Nbr}$ - total number of transmission lines in power systems.

\section{Voltage Profile Improvement}

For minimizing the voltage deviation in PQ buses, the objective function becomes:

$F=P L+\omega_{v} \times V D$

Where VD - voltage deviation, $\omega_{\mathrm{v}}$ - is a weighting factor of voltage deviation.

Voltage deviation given by:

$V D=\sum_{i=1}^{N p q}\left|V_{i}-1\right|$

Where Npq- number of load buses

\section{Equality Constraint}

The equality constraint of the problem is represented by the power balance equation, where the total power generation must cover the total power demand and the power losses:

$P_{G}=P_{D}+P_{L}$

Where $\mathrm{P}_{\mathrm{G}^{-}}$total power generation, $\mathrm{P}_{\mathrm{D}}$ - total power demand.

\section{Inequality Constraints}

The inequality constraints in the power system as well as the limits created to ensure system security. Upper and lower bounds on the active power of slack bus (Pg), and reactive power of generators $\left(\mathrm{Q}_{\mathrm{g}}\right)$ are written in mathematically as follows:

$$
\begin{aligned}
& P_{\text {gslack }}^{\min } \leq P_{\text {gslack }} \leq P_{\text {gslack }}^{\max } \\
& Q_{g i}^{\min } \leq Q_{g i} \leq Q_{g i}^{\max }, i \in N_{g}
\end{aligned}
$$


Upper and lower bounds on the bus voltage magnitudes $\left(\mathrm{V}_{\mathrm{i}}\right)$ :

$V_{i}^{\min } \leq V_{i} \leq V_{i}^{\max }, i \in N$

Upper and lower bounds on the transformers tap ratios $\left(\mathrm{T}_{\mathrm{i}}\right)$ :

$T_{i}^{\min } \leq T_{i} \leq T_{i}^{\max }, i \in N_{T}$

Upper and lower bounds on the compensators reactive powers $\left(\mathrm{Q}_{\mathrm{c}}\right)$ :

$Q_{c}^{\min } \leq Q_{c} \leq Q_{C}^{\max }, i \in N_{C}$

Where $\mathrm{N}$ is the total number of buses, $\mathrm{N}_{\mathrm{T}}$ is the total number of Transformers; $\mathrm{N}_{\mathrm{c}}$ is the total number of shunt reactive compensators.

\section{Basic Teaching-Learning-Based Optimization}

Based on the consequence of the influence of a teacher on the output of students in a class, Teaching-Learning-Based Optimization (TLBO) optimization algorithm has been framed. It is a population-based method $\&$ there are numbers of different design variables. Different subjects offered to learners and the learners" result is analogous to the "fitness" \& it act as different design variables in TLBO. The most excellent solution is analogous to Teacher in TLBO. The algorithm consists of first part "Teacher Phase" and the second "Learner Phase". Learning from the teacher is the "Teacher Phase" means and learning through the interaction between learners is the "Learner Phase". The execution of TLBO as follows,

\section{1) Initialization}

Following are the notations used for describing the TLBO:

$L$ : "class size "of the learners;

$C$ : list of the courses offered to the learners to learn;

$M A X I T$; number of maximum iterations.

In search space bounded the population $Y$ is arbitrarily initialized by a by matrix of $L$ rows and $C$ columns. In ith learner . the $j$ th parameter is assigned values arbitrarily by equation

$y_{(i, j)}^{0}=y_{j}^{\min }+\operatorname{rand} \times\left(y_{j}^{\max }-y_{j}^{\min }\right)$

Within the range $(0,1)$ "rand" represents a uniformly distributed arbitrary variable, minimum and maximum value for $j$ th parameter is represented by $y_{j}^{\max }$ and $y_{j}^{\text {min }}$. For the generation $g$ parameters of the ith learner are given by,

$Y_{(i)}^{g}=\left[y_{(i, 1)}^{g}, y_{(i, 2)}^{g}, y_{(i, 3)}^{g}, \ldots, y_{(i, j)}^{g}, \ldots, y_{(i, D)}^{g}\right]$ 


\section{2) Teacher Phase}

At generation $g$ the mean parameter $E_{\mathrm{g}}$ of each subject learners in the class is given as,

$E^{g}=\left[e_{1}^{g}, e_{2}^{g}, \ldots, e_{j}^{g}, \ldots, e_{D}^{g}\right]$

The teacher $X_{\text {Teacher }}^{g}$ with the minimum objective function value of the learner is considered as for respective iteration. Shifting the mean of the learners towards its teacher is done by Teacher phase. An arbitrary weighted differential vector is formed to obtain a new-fangled set of improved learners from the current mean, desired mean parameters and is added to the existing population of learners.

$\operatorname{Ynew}_{(i)}^{g}=Y_{(i)}^{g}+\operatorname{rand} \times\left(Y_{\text {Teacher }}^{g}-T e_{F} E^{g}\right)$

The value of mean to be changed is decided by "Te $e_{F}$ - teaching factor. Value of $T_{F}$ can be either 1 or 2 . With equal probability the value of $T e_{F}$ is decided arbitrarily as,

$T e_{F}=\operatorname{round}[1+\operatorname{rand}(0.1)\{2-1\}]$

The value of $T_{F}$ value is arbitrarily decided by the algorithm using Equation (14). In generation $g$ if $\operatorname{Ynew}_{(i)}^{g}$ is superior learner than $Y_{(i)}^{g}$, than it swap the inferior learner $Y_{(i)}^{g}$ in the matrix.

\section{3) Learner Phase}

In this phase the mutual interaction tends to augment the knowledge of the learner. The arbitrary inter- action among learners improves the knowledge. For a given learner $Y_{(i)}^{g}$ another learner $Y_{(r)}^{g}$ is arbitrarily selected $(i \neq r)$. In the learner phase the $i$ th parameter of the matrix $Y_{\text {new }}$ is given as,

$$
Y_{(i)}^{g}=\left\{\begin{array}{l}
Y_{(i)}^{g}+\operatorname{rand} \times\left(Y_{(i)}^{g}-Y_{(r)}^{g}\right) \\
\text { if } f\left(Y_{(i)}^{g}\right)<f\left(Y_{(r)}^{g}\right) \\
Y_{(i)}^{g}+\text { rand } \times\left(Y_{(r)}^{g}-Y_{(i)}^{g}\right) \text { otherwise }
\end{array}\right.
$$

\section{4) Algorithm Termination}

After MAXIT conditions satisfied the algorithm is terminated.

\section{Modified Teaching-Learning-Based Optimization (MTLBO) Algorithm}

The principles of teaching-learning approach is imitated in Teaching-Learning-Based Optimization (TLBO) \& draw analogy with the real class room. Teaching-learning process is an iterative process where in the continuous interaction takes place for the transfer of knowledge. A parameter known as "weight" is added in the Equations (13) and (15) of original TLBO algorithm. In contrast to the original TLBO, while computing the new learner values the part of its previous 
value is considered and decided by a weight factor " $w f$ ' in our Modified Teaching-Learning-Based Optimization (MTLBO) algorithm. During the early stages of the search Individuals are encouraged to sample diverse zones of the exploration space. It is important to adjust the movements of trial solutions finely \& they can explore the interior of a relatively small space in the later stages. Value of the weight factor reduced linearly with time from a maximum to a minimum value by,

$w f=w f_{\text {max }}-\left(\frac{w f_{\text {max }}-w f_{\min }}{\text { maxiteration }}\right) * i$

The maximum and minimum values of weight factor $w$ are $w f_{\max }$ and $w f_{\min }$, " $I$ " - iteration is the current iteration number and max iteration is the maximum number of iterations. $w f_{\max } \&$ $w f_{\text {min }}$ are selected between $0.9-0.1$, respectively. New set of improved learners in the teacher phase can be,

$\operatorname{Ynew}_{(i)}^{g}=w f * Y_{(i)}^{g}+\operatorname{rand} *\left(Y_{\text {Teacher }}^{g}-T e_{F} E^{g}\right)$

And in learner phase a set of improved learners are,

$$
\operatorname{Ynew}_{(i)}^{g}=\left\{\begin{array}{l}
w f * X_{(i)}^{g}+\operatorname{rand} \times\left(Y_{(i)}^{g}-Y_{(r)}^{g}\right) \\
\text { if } f\left(Y_{(i)}^{g}\right)<f\left(Y_{(r)}^{g}\right) \\
w f * Y_{(i)}^{g}+\operatorname{rand} \times\left(Y_{(r)}^{g}-Y_{(i)}^{g}\right) \text { otherwise }
\end{array}\right.
$$

\section{Simulation Results}

Modified Teaching-Learning-Based Optimization (MTLBO) algorithm has been tested in practical 191 test system and the following results have been obtained. In Practical 191 test bus system - Number of Generators $=20$, Number of lines $=200$, Number of buses $=191$ Number of transmission lines $=55$. Table 1 shows the optimal control values of practical 191 test system obtained by MTLBO method. And table 2 shows the results about the value of the real power loss by obtained by Modified Teaching-Learning-Based Optimization (MTLBO) algorithm.

Table 1: Optimal Control values of Practical 191 utility (Indian) system by MTLBO method

\begin{tabular}{|c|c|c|c|}
\hline VG1 & 1.1000 & VG 11 & 0.9000 \\
\hline $\mathrm{VG} 2$ & 0.7200 & $\mathrm{VG} 12$ & 1.0000 \\
\hline VG 3 & 1.0100 & VG 13 & 1.0000 \\
\hline VG 4 & 1.0100 & VG 14 & 0.9000 \\
\hline VG 5 & 1.1000 & VG 15 & 1.0000 \\
\hline VG 6 & 1.1000 & VG 16 & 1.0000 \\
\hline VG 7 & 1.1000 & VG 17 & 0.9000 \\
\hline VG 8 & 1.0100 & VG 18 & 1.0000 \\
\hline VG 9 & 1.1000 & VG 19 & 1.1000 \\
\hline VG 10 & 1.0100 & VG 20 & 1.1000 \\
\hline
\end{tabular}




\begin{tabular}{|c|c|c|c|c|c|}
\hline T1 & 1.0000 & $\mathrm{~T} 21$ & 0.9000 & T41 & 0.9000 \\
\hline $\mathrm{T} 2$ & 1.0000 & $\mathrm{~T} 22$ & 0.9000 & T42 & 0.9000 \\
\hline T3 & 1.0000 & $\mathrm{~T} 23$ & 0.9000 & T43 & 0.9100 \\
\hline $\mathrm{T} 4$ & 1.1000 & T24 & 0.9000 & T44 & 0.9100 \\
\hline $\mathrm{T} 5$ & 1.0000 & $\mathrm{~T} 25$ & 0.9000 & T45 & 0.9100 \\
\hline T6 & 1.0000 & T26 & 1.0000 & T46 & 0.9000 \\
\hline $\mathrm{T} 7$ & 1.0000 & T27 & 0.9000 & T47 & 0.9100 \\
\hline $\mathrm{T} 8$ & 1.0100 & $\mathrm{~T} 28$ & 0.9000 & T48 & 1.0000 \\
\hline T9 & 1.0000 & T29 & 1.0100 & T49 & 0.9000 \\
\hline T10 & 1.0000 & T30 & 0.9000 & T50 & 0.9000 \\
\hline T11 & 0.9000 & T31 & 0.9000 & T51 & 0.9000 \\
\hline $\mathrm{T} 12$ & 1.0000 & T32 & 0.9000 & T52 & 0.9000 \\
\hline T13 & 1.0100 & T33 & 1.0100 & T53 & 1.0000 \\
\hline T14 & 1.0100 & T34 & 0.9000 & T54 & 0.9000 \\
\hline T15 & 1.0100 & T35 & 0.9000 & T55 & 0.9000 \\
\hline
\end{tabular}

Table 2: Optimum real power loss values obtained for practical 191 utility (Indian) system by MTLBO method.

\begin{tabular}{|l|l|}
\hline Real power Loss (MW) & MTLBO \\
\hline Min & 149.1213 \\
\hline Max & 154.1298 \\
\hline Average & 151.2010 \\
\hline
\end{tabular}

\section{Conclusion}

In this paper a novel approach Modified Teaching-Learning-Based Optimization (MTLBO) algorithm used to solve reactive power problem, considering various generator constraints, has been successfully applied. Also it has been found that TLBO algorithm slow in convergence due to its high concentration in the accuracy. The performance of the proposed Modified TeachingLearning-Based Optimization (MTLBO) algorithm has been has been tested in practical 191 test bus system and simuation results expose about the decrease of real power loss \& volatge profiles are within the limits.

\section{References}

[1] O.Alsac,and B. Scott, "Optimal load flow with steady state security”,IEEE Transaction. PAS -1973, pp. 745-751.

[2] Lee K Y ,Paru Y M , Oritz J L -A united approach to optimal real and reactive power dispatch , IEEE Transactions on power Apparatus and systems 1985: PAS-104 : 1147-1153

[3] A.Monticelli , M .V.F Pereira ,and S. Granville, "Security constrained optimal power flow with post contingency corrective rescheduling", IEEE Transactions on Power Systems :PWRS-2, No. 1, pp.175-182.,1987.

[4] Deeb N, Shahidehpur S.M ,Linear reactive power optimization in a large power network using the decomposition approach. IEEE Transactions on power system 1990: 5(2) : 428-435

[5] E. Hobson ,'Network consrained reactive power control using linear programming, ' IEEE Transactions on power systems PAS -99 (4) ,pp 868=877, 1980 
[6] K.Y Lee ,Y.M Park, and J.L Oritz, "Fuel -cost optimization for both real and reactive power dispatches”, IEE Proc; 131C,(3), pp.85-93.

[7] M.K. Mangoli, and K.Y. Lee, "Optimal real and reactive power control using linear programming", Electr.Power Syst.Res, Vol.26, pp.1-10,1993.

[8] K.Anburaja, "Optimal power flow using refined genetic algorithm", Electr.Power Compon.Syst , Vol. 30, 1055-1063,2002.

[9] D. Devaraj, and B. Yeganarayana, "Genetic algorithm based optimal power flow for security enhancement", IEE proc-Generation.Transmission and. Distribution; 152, 6 November 2005.

[10] R. V. Rao, V. J. Savsani and D. P. Vakharia, "Teaching- Learning-Based Optimization: A Novel Method for Con- strained Mechanical Design Optimization Problems," Computer-Aided Design, Vol. 43, No. 1, 2011, pp. 303- 315. doi:10.1016/j.cad.2010.12.015 .

[11] R. V. Rao, V. J. Savsani and D. P. Vakharia, "Teach- ing-Learning-Based Optimization: An Optimization Me- thod for Continuous Non-Linear Large Scale Problems," INS 9211 No. of Pages 15, Model 3G 26 August 2011.

[12] R. V. Rao, V. J. Savsani and J. Balic, "Teaching Learning Based Optimization Algorithm for Constrained and Un- constrained Real Parameter Optimization Problems," En- gineering Optimization, Vol. 44, No. 12, 2012, pp. 1447- 1462. doi:10.1080/0305215X.2011.652103.

[13] R. V. Rao and V. J. Savsani, "Mechanical Design Opti- mization Using Advanced Optimization Techniques," Springer-Verlag, London, 2012. doi:10.1007/978-1-4471-2748-2

[14] V. Toğan, "Design of Planar Steel Frames Using Teach- ing-Learning Based Optimization," Engineering Struc- tures, Vol. 34, 2012, pp. 225-232. doi:10.1016/j.engstruct.2011.08.035

[15] R. V. Rao and V. D. Kalyankar, "Parameter Optimization of Machining Processes Using a New Optimization Algo- rithm," Materials and Manufacturing Processes, Vol. 27, No. 9, 2011, pp. 978 985. doi:10.1080/10426914.2011.602792.

[16] S. C. Satapathy and A. Naik, "Data Clustering Based on Teaching-Learning-Based Optimization. Swarm, Evolu- tionary, and Memetic Computing," Lecture Notes in Com- puter Science, Vol. 7077, 2011, pp. 148-156, doi:10.1007/978-3-642-27242-4_18.

*Corresponding author.

E-mail address: gklenin @gmail.com 


\section{Intentionally Blank}




\section{Intentionally Blank}

